\title{
Effect of Magnesium Sulfate Nebulization on Stress Response Induced Tracheal Intubation; Prospective, Randomized Study
}

\author{
Mohamed Said Mostafa Elmeligy, Mohamed Fouad Mohamed Elmeliegy \\ Anaesthesia Department, Benha University, Benha, Egypt \\ Email: Mohmedsaid808@yahoo.com,Mohamedfouaaaaad2020@gmail.com
}

How to cite this paper: Elmeligy, M.S.M. and Elmeliegy, M.F.M. (2021) Effect of Magnesium Sulfate Nebulization on Stress Response Induced Tracheal Intubation; Prospective, Randomized Study. Open Journal of Anesthesiology, 11, 128-135. https://doi.org/10.4236/ojanes.2021.114012

Received: November 10, 2020

Accepted: April 23, 2021

Published: April 27, 2021

Copyright $\odot 2021$ by author(s) and Scientific Research Publishing Inc. This work is licensed under the Creative Commons Attribution International License (CC BY 4.0).

http://creativecommons.org/licenses/by/4.0/ (c) (i) Open Access

\begin{abstract}
Background and Aims: Multiple, nonpharmacological and pharmacological measures have been used for attenuating stress response of intubation with variable results. N-methyl-D-aspartate (NMDA) receptors have a role in nociception and inflammation. NMDA receptors are located in peripheral and the central nervous system. Magnesium is also a NMDA receptor blocker. Aim of the Study: To evaluate the effect of nebulized magnesium sulfate on reduce the stress response induced tracheal intubation Material and Methods: Following institutional ethical committee approval and written informed consent, a prospective randomized double-blinded study was conducted in 100 cases divided into two equal groups. Patients included in the study were of either gender belonging to American Society of Anesthesiologists (ASA) status 1 or 2 undergoing elective surgery requiring tracheal intubation. Patients will be recruited in the study divided into two equal groups; Patients in Group A: will receive nebulized magnesium sulfate in $3 \mathrm{ml}$ (240 $\mathrm{mg}$ ) over $15 \mathrm{~min}$. While group B: will receive nebulized normal saline in $3 \mathrm{ml}$ over $15 \mathrm{~min}$, ending $5 \mathrm{~min}$ before the induction of anesthesia. SBP, DBP, HR, and blood glucose level will be measured at the following intervals; Baseline (before induction), after premedication (sedation), after induction, after ETT intubation, $3 \mathrm{~min}$ later, $6 \mathrm{~min}$ later. Results: Preoperative magnesium sulfate nebulization has a significant effect ( $\mathrm{p}$ value $<0.001$ ) on attenuating the stress response (SBP, DBP, HR, and SBG) to tracheal intubation at the following intervals; post ETT intubation, $3 \mathrm{~min}$ later, and $6 \mathrm{~min}$ later. Conclusion: Magnesium sulfate significantly reduces the stress response of intubation.
\end{abstract}

\section{Keywords}

Magnesium, Intubation 


\section{Introduction}

The STRESS response to endotracheal intubation is a common event that we find it daily in all cases in operating room, due to the release of endogenous catecholamine's [1]. This inappropriate response may affect the outcome of cases that operated under general anesthesia with ETT intubation, especially in patients with cardiovascular disease like uncontrolled hypertension and ischemic heart diseases [2]. The management of this response is important as it prevents adverse events, like tachycardia, systemic hypertension, pulmonary hypertension, and arrhythmias [3]. A lot of drugs are the subject of studies, including those with excellent results, such as magnesium sulfate [4].

The mechanism of magnesium sulfate action for attenuating the stress response results from the inhibition of catecholamine releasing from the adrenal medulla, keeping the plasma concentration of epinephrine at a fixed level, and also decreasing the circulating norepinephrine level when compared to that of a control group [5]. It also has a vasodilation effect on systemic and coronary blood vessels by blocking calcium ion in vascular smooth muscle [6].

The aim of this study was to study the effects of nebulized magnesium sulfate on hemodynamics during intubation.

\section{Patient and Methods}

Following institutional ethical committee approval and written informed consent, a prospective randomized double-blinded study. After written informed consent was given, 100 patients, ASA 1 or 2, aged between 20 - 50 years, scheduled for elective surgery with Orotracheal Intubation (OTI) were assessed for eligibility. Patients will be recruited in the study divided into two equal groups; Patients in Group A: will receive nebulized magnesium sulfate in $3 \mathrm{ml}(240 \mathrm{mg})$ over $15 \mathrm{~min}$, While group B: will receive nebulized normal saline in $3 \mathrm{ml}$ over 15 min, ending 5 min before the induction of anesthesia. SBP, DBP, HR, and blood glucose level will be measured at the following intervals; Baseline (before induction), after premedication (sedation), after induction, after ETT intubation, 3 min later, 6 min later.

Patients that excluded from the study those with history of hypersensitivity to magnesium sufate, coronary ischemic disease, atrioventricular block of any degree, known cardiac arrhythmias, heart failure, renal failure, on beta blockers or calcium channel blockers, expected difficult intubation. Also Patients who had epidural or spinal block before general anesthesia, who required more than two attempts at intubation were excluded. In the other side Patients who met the inclusion criteria were identified and received an identification number, according to the order of inclusion in the study.

After orotracheal intubation, anesthesia was maintained with $2 \%$ inhaled sevoflurane, and new measurements were taken three and six minutes after intubation ( 3 post-OTI and 6 post-OTI). Hypertension was considered when the BP values were $20 \%$ above baseline values or SBP > $140 \mathrm{mmHg}$. Hypotension was 
considered when BP values were lower than $20 \%$ of baseline or SBP $<90 \mathrm{mmHg}$. Tachycardia was considered when HR was higher than $20 \%$ of baseline or HR > $100 \mathrm{bpm}$. Bradycardia was considered when HR values were lower than $50 \mathrm{bpm}$.

The primary endpoint was to determine the effects of magnesium sulfate (Group M) on SBP immediately after intubation (post-OTI). The secondary endpoints were the assessment of changes in SBP, DBP, HR, and SBG before and after the administration of study drugs, its changes within six minutes after intubation, as well the identification of adverse events with the use of both techniques Statistical analysis was performed with the XLSTAT software for Excel A $\mathrm{P}$ value $<0.05$ was considered significant. Data were expressed as mean $\pm \mathrm{SD}$ (mean, standard deviation).

\section{Result}

The age and weight were comparable in the two groups (Table 1). There was no significant difference in attenuating stress response of OTI at all intervals.

As showing in (Table 2) regarding SBP there was significant effect of mgso4 nebulization ( $\mathrm{P}$ value $<0.001$ ) on decreasing SBP at the following intervals; post nebulization, post induction, post OTI, 3 min later, 6 min later.

As showing in (Figure 1) regarding SBP there was significant effect of mgso4 nebulization $(\mathrm{P}$ value $<0.001$ ) on decreasing SBP at the following intervals; post nebulization, post induction, post OTI, 3 min later, 6 min later.

Table 1. Demographic data with median and IQR.

\begin{tabular}{lcccccc}
\hline & \multicolumn{2}{c}{ Mg group } & \multicolumn{2}{c}{ Control group } & \multicolumn{2}{c}{ Statistical test } \\
& Median & IQR & Median & IQR & Palue \\
\cline { 2 - 6 } age & 23.0 & $20.0-50.0$ & 23.0 & $21.0-28.0$ & 0.68 & 0.50 \\
weight & 70.0 & $62.0-70.5$ & 65.0 & $65.0-72.0$ & 0.02 & 0.98 \\
\hline
\end{tabular}

Table 2. SBP changes after mgso4 nebulization at different intervals.

\begin{tabular}{|c|c|c|c|c|c|c|}
\hline & \multicolumn{2}{|c|}{ Mg group } & \multicolumn{2}{|c|}{ Control group } & \multirow{2}{*}{$\begin{array}{c}\text { Statistical test } \\
\left(\mathrm{Z}_{\mathrm{MWU}}\right)\end{array}$} & \multirow{2}{*}{$P$ value } \\
\hline & Median & IQR & Median & IQR & & \\
\hline \multicolumn{7}{|l|}{ SBP } \\
\hline Baseline & 130.5 & $122.0-135.0$ & 130.0 & $125.0-135.0$ & 0.33 & 0.74 \\
\hline Post MID & 120.0 & $112.0-125.0$ & 125.0 & $119.0-130.0$ & 3.03 & $0.002^{* *}$ \\
\hline Post nebuliz & 112.5 & $110.0-121.0$ & 123.0 & $120.0-128.0$ & 4.48 & $<0.001^{* *}$ \\
\hline Post induction & 97.0 & $95.0-101.0$ & 103.0 & $100.0-105.0$ & 3.77 & $<0.001^{\star *}$ \\
\hline Post oti & 118.0 & $108.0-119.0$ & 127.0 & $125.0-130.0$ & 6.29 & $<0.001^{\star *}$ \\
\hline 3 min later & 103.5 & $101.0-106.0$ & 119.0 & $118.0-125.0$ & 5.68 & $<0.001^{\star *}$ \\
\hline 6 min later & 101.0 & $100.0-102.0$ & 121.0 & $115.0-125.0$ & 6.41 & $<0.001^{\star *}$ \\
\hline
\end{tabular}


As regard DBP changes as showed in (Table 3 ) there was no significant effect of mg so4 nebulization on DBP AT post induction and post OTI.

But there was a significant $(\mathrm{P}$ value $<0.001)$ attenuation of DBP increase at 3 min and 6 min after intubation.

As regard DBP changes as showed in (Figure 2) there was no significant effect of $\mathrm{mg}$ so4 nebulization on DBP AT post induction and post OTI.

But there was a significant $(\mathrm{P}$ value $<0.001)$ attenuation of DBP increase at 3 min and 6 min after intubation.

As regard HR changes as showed in (Table 4) there was no significant effect of $\mathrm{mg}$ so4 nebulization on $\mathrm{HR}$ at post induction.

But there was a significant $(P$ value $<0.001)$ attenuation of $H R$ increase at post OTI, 3 min later and 6 min later (after intubation).

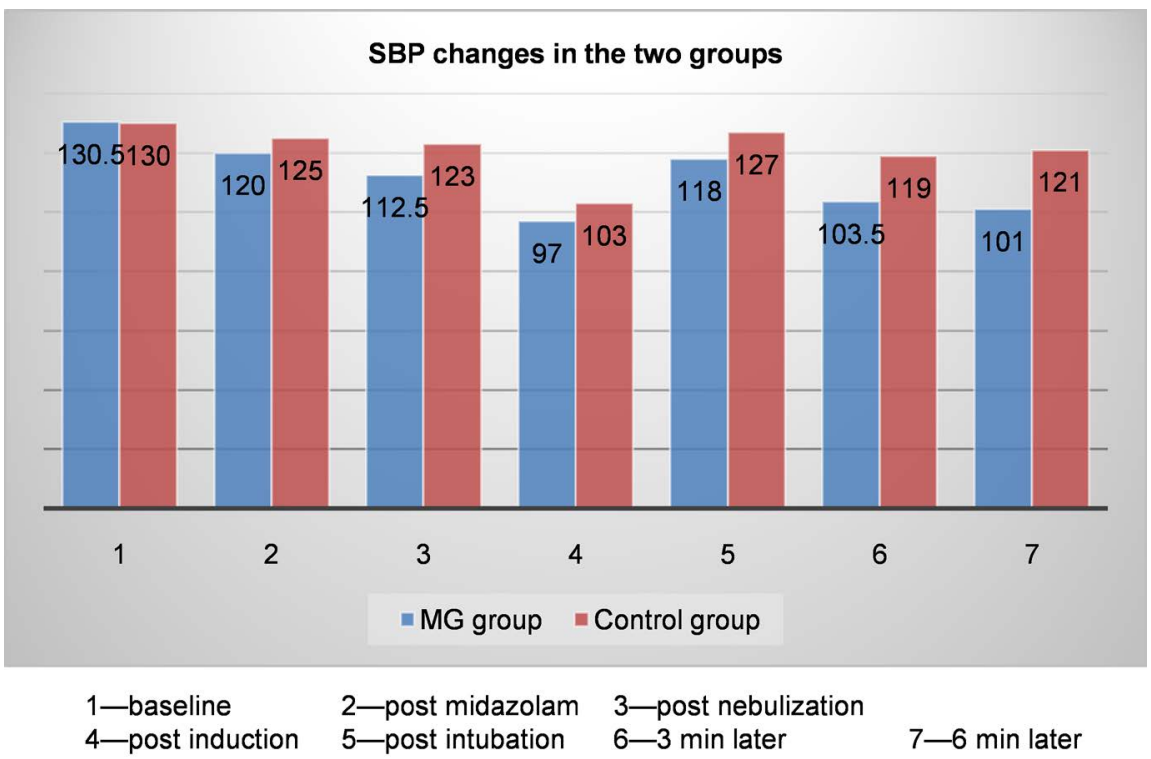

Figure 1. SBP changes after mgso4 nebulization at different intervals.

Table 3. DBP changes after mgso4 nebulization at different intervals.

\begin{tabular}{ccccccc}
\hline & \multicolumn{2}{c}{ Mg group } & \multicolumn{2}{c}{ Control group } & Statistical test & P value \\
& Median & IQR & Median & IQR & (ZMwU $)$ & \\
\cline { 2 - 5 } DBP & & & & & & \\
Baseline & 76.0 & $68.0-85.0$ & 77.0 & $69.0-85.0$ & 1.07 & 0.28 \\
Post MID & 70.0 & $65.0-80.0$ & 71.5 & $65.0-81.0$ & 0.67 & 0.50 \\
Post nebuliz & 67.0 & $62.0-73.0$ & 69.0 & $67.0-78.0$ & 2.41 & $0.016^{*}$ \\
Post induction & 60.5 & $56.0-65.0$ & 65.5 & $60.0-68.0$ & 2.95 & $0.003^{* *}$ \\
Post oti & 73.5 & $70.0-75.0$ & 78.0 & $74.0-80.0$ & 2.68 & $0.007^{* *}$ \\
3 min later & 66.5 & $65.0-72.0$ & 73.0 & $72.0-77.0$ & 3.9 & $<0.001^{* *}$ \\
6 min later & 64.5 & $59.0-67.0$ & 74.5 & $69.0-77.0$ & 4.81 & $<0.001^{* *}$ \\
\hline
\end{tabular}




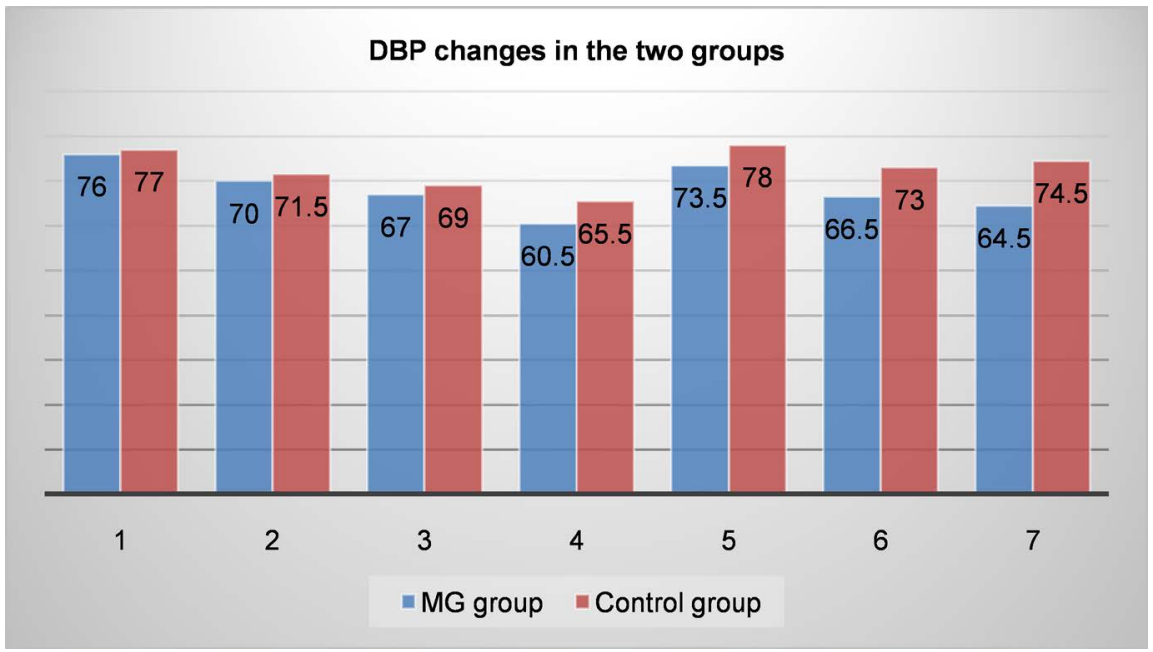

Figure 2. DBP changes after mgso4 nebulization at different intervals.

Table 4. HR changes after mgso4 nebulization at different intervals.

\begin{tabular}{|c|c|c|c|c|c|c|}
\hline & \multicolumn{2}{|c|}{ Mg group } & \multicolumn{2}{|c|}{ Control group } & \multirow{2}{*}{$\begin{array}{c}\text { Statistical test } \\
\left(\mathrm{Z}_{\mathrm{MWU}}\right)\end{array}$} & \multirow{2}{*}{$P$ value } \\
\hline & Median & IQR & Median & IQR & & \\
\hline \multicolumn{7}{|l|}{$\mathrm{HR}$} \\
\hline Baseline & 78.5 & $77.0-84.0$ & 76.5 & $74.0-78.0$ & 2.54 & $0.011^{\star}$ \\
\hline Post MID & 73.5 & $71.0-74.0$ & 72.5 & $71.0-75.0$ & 0.14 & 0.89 \\
\hline Post nebuliz & 71.0 & $70.0-75.0$ & 74.5 & $73.0-77.0$ & 2.24 & $0.025^{*}$ \\
\hline Post induction & 79.0 & $77.0-82.0$ & 79.0 & $73.0-79.0$ & 2.17 & $0.03^{*}$ \\
\hline Post oti & 75.5 & $75.0-80.0$ & 80.5 & $80.0-81.0$ & 4.33 & $<0.001^{\star \star}$ \\
\hline 3 min later & 70.0 & $68.0-71.0$ & 75.0 & $75.0-77.0$ & 6.59 & $<0.001^{\star \star}$ \\
\hline 6 min later & 66.5 & $65.0-68.0$ & 74.0 & $73.0-75.0$ & 6.49 & $<0.001^{\star *}$ \\
\hline
\end{tabular}

As regard HR changes as showed in (Figure 3) there was no significant effect of mgso4 nebulization on HR at post induction.

But there was a significant $(\mathrm{P}$ value $<0.001)$ attenuation of $\mathrm{HR}$ increase at post OTI, 3 min later and 6 min later (after intubation).

As regard SBG changes as showed in (Table 5) there was no significant effect of mgso4 nebulization on SBG at post nebulization, post induction and post OTI.

But there was a significant $(\mathrm{P}$ value $<0.001)$ attenuation of SBG increase at 3 min later and 6 min later (after intubation).

As regard SBG changes as showed in (Figure 4) there was no significant effect of mgso4 nebulization on SBG at post nebulization, post induction and post OTI.

But there was a significant $(\mathrm{P}$ value $<0.001)$ attenuation of SBG increase at 3 min later and 6 min later (after intubation). 
Table 5. SBG changes after mgso4 nebulization at different intervals.

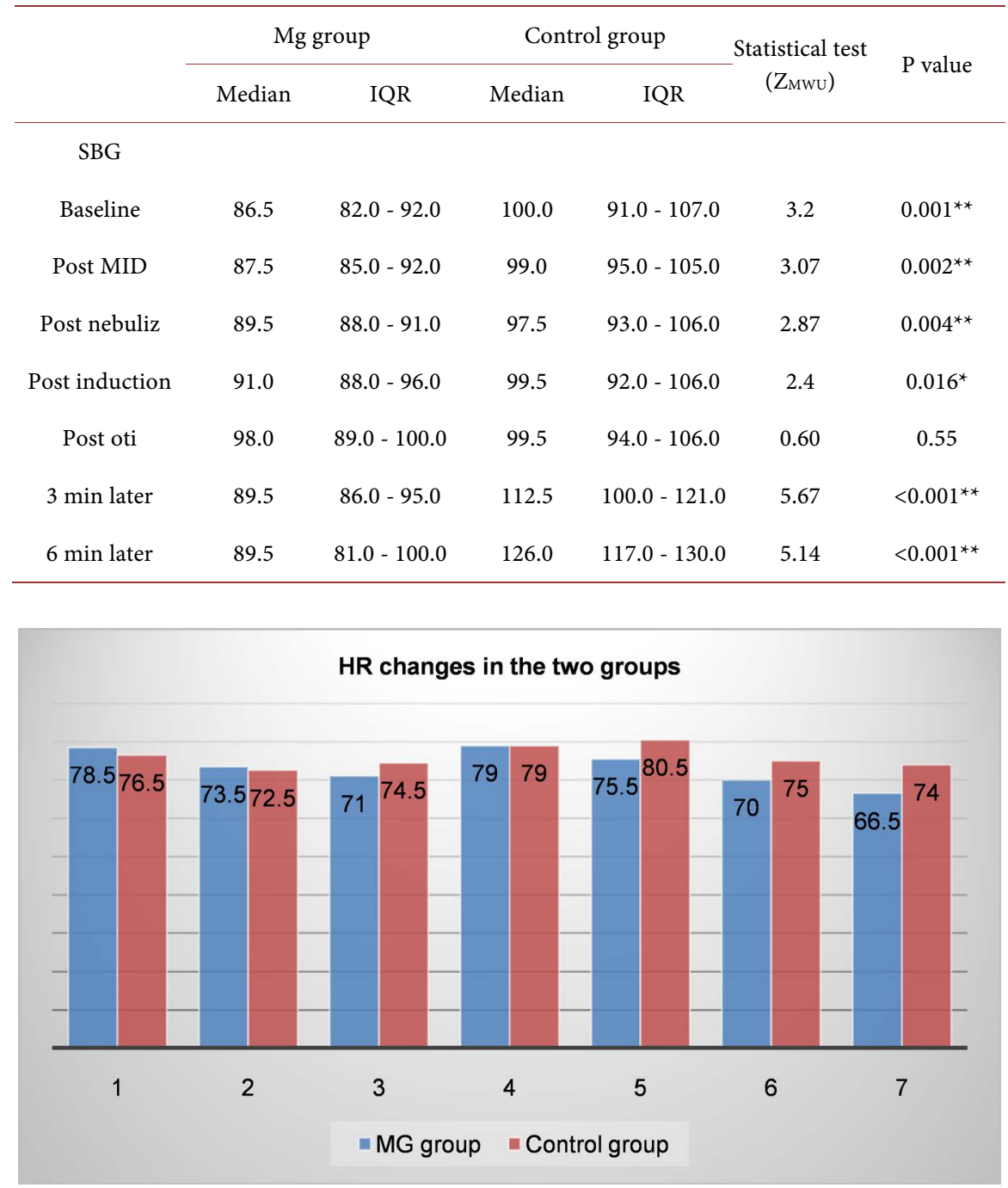

Figure 3. HR changes after mgso4 nebulization at different intervals.

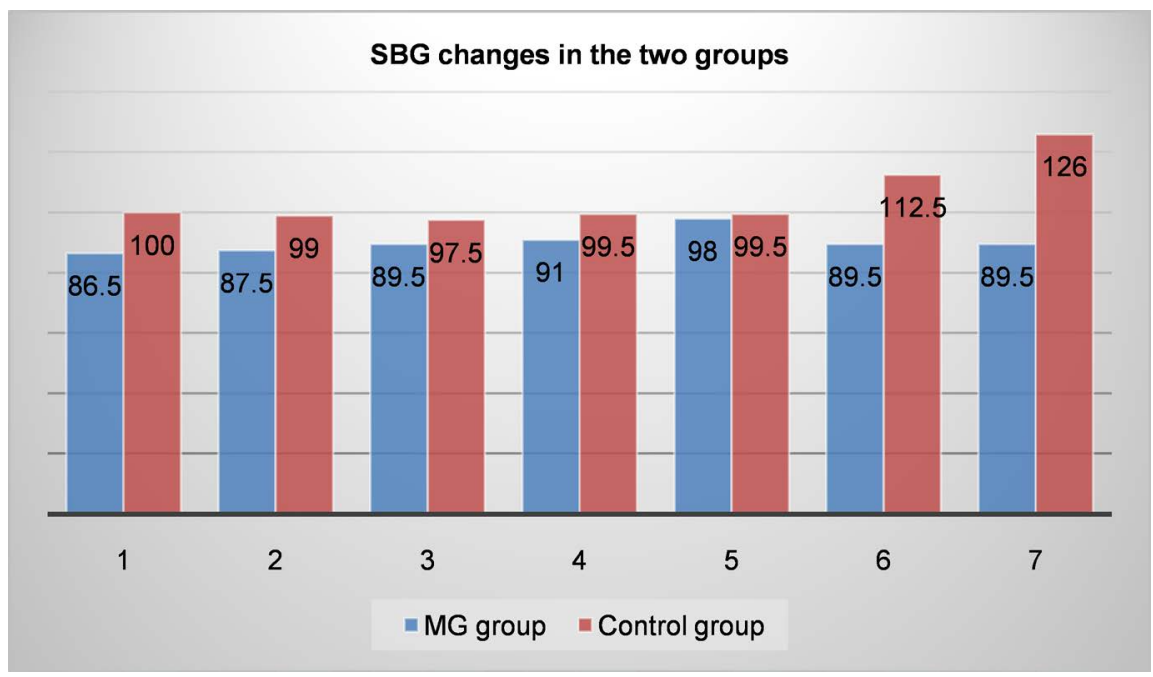

Figure 4. SBG changes after mgso4 nebulization at different intervals. 


\section{Discussion}

Calcium has a major role in the release of catecholamines from the adrenal medulla and adrenergic nerve terminals in response to the stimulation by sympathetic nervous system.

Magnesium competes with calcium for binding to the membrane channels [7]. Hence, magnesium acts as a calcium antagonist and can modify the responses that mediated by calcium. Hence, $\mathrm{MgSO}_{4}$ blocks release of catecholamine stores and decrease responses to adrenergic stimulations [8].

Our study agree with Laurant et al. [9] who showed that IV $\mathrm{MgSO}_{4}$ attenuate the release both catecholamine and vasopressin in mesenteric resistance arteries of spontaneously hypertensive rats.

Agree with James M.F. [10] who said that Magnesium sulfate is utilized in stressful conditions with catecholamine excess such as tetanus, pheochromocytoma.

Agree with Nakashima H. et al., [11] who approved that Magnesium sulfate is used in stressful conditions such as ST elevation anterior myocardial infarction.

Also agree with Turlapaty P.D. et al., [12] who approved that MgSO4 also directly reduces smooth muscle tonicity and subsequently vascular contraction

Therefore, $\mathrm{MgSO}_{4}$ is useful to decrease systemic hypertension, as using for treatment of pregnancy induced hypertension.

Borazan H. et al. [13] approved the efficiency of preoperative oral magnesium lozenge and found that the incidence and severity of postoperative sore throat (POST) is significantly decreased.

Also Our study agree with Gupta et al. [14] who assessed the local efficiency of preoperative nebulization of magnesium sulfate and found that the incidence and severity of POST (postoperative sore throat) were reduced at rest and on swallowing at all-time points $(\mathrm{P}<0.05)$ post operatively after extubation.

\section{Conclusion}

Our study showed that magnesium sulfate nebulization has a significant effect to attenuate the stress response to Endotracheal intubation in the form of attenuating increase of Systolic Blood Pressure(SBP), Diastolic Blood Pressure(DBP), Heart Rate (HR), and Serum Blood Glucose(SBG) specially in (3min.and 6 min.) later to intubation, Finally, we can say that preoperative nebulized magnesium sulfate has good efficacy and safety for hemodynamic control during laryngoscopy and intubation, presenting as an option to mitigate the stimulation of upper airway in patients undergoing general anesthesia.

\section{Conflicts of Interest}

The authors declare no conflicts of interest regarding the publication of this paper.

\section{References}

[1] Ratnaraj, J., Todorov, A., McHugh, T., Cheng, M.A. and Lauryssen, C. (2002) Ef- 
fects of Decreasing Endotracheal Tube Cuff Pressures during Neck Retraction for Anterior Cervical Spine Surgery. Journal of Neurosurgery, 97, 176-179. https://doi.org/10.3171/spi.2002.97.2.0176

[2] Canbay, O., Celebi, N., Sahin, A., Celiker, V., Ozgen, S. and Aypar, U. (2008) Ketamine Gargle for Attenuating Postoperative Sore Throat. British Journal of Anaesthesia, 100, 490-493. https://doi.org/10.1093/bja/aen023

[3] Agarwal, A., Nath, S.S., Goswami, D., Gupta, D., Dhiraaj, S. and Singh, P.K. (2006) An Evaluation of the Efficacy of Aspirin and Benzydamine Hydrochloride Gargle for Attenuating Postoperative Sore Throat: A Prospective, Randomized, Single-Blind Study. Anesthesia \& Analgesia, 103, 1001-1003.

https://doi.org/10.1213/01.ane.0000231637.28427.00

[4] Lin, C.Y., Tsai, P.S., Hung, Y.C. and Huang, C.J. (2010) L-Type Calcium Channels Are Involved in Mediating the Anti-Inflammatory Effects of Magnesium Sulphate. British Journal of Anaesthesia, 104, 44-51. https://doi.org/10.1093/bja/aep336

[5] Higgins, P.P., Chung, F. and Mezei, G. (2002) Postoperative Sore Throat after Ambulatory Surgery. British Journal of Anaesthesia, 88, 582-584.

https://doi.org/10.1093/bja/88.4.582

[6] Turpin, F., Dallérac, G. and Mothet, J.P. (2011) Electrophysiological Analysis of the Modulation of NMDA-Receptors Function by D-Serine and Glycine in the Central Nervous System. Unnatural Amino Acids, 794, 299-312. https://doi.org/10.1007/978-1-61779-331-8 20

[7] Sumathi, P.A., Shenoy, T., Ambareesha, M. and Krishna, H.M. (2008) Controlled Comparison between Betamethasone Gel and Lidocaine Jelly Applied over Tracheal Tube to Reduce Postoperative Sore Throat, Cough, and Hoarseness of Voice. British Journal of Anaesthesia, 100, 215-218. https://doi.org/10.1093/bja/aem341

[8] Zhu, M.M., Zhou, Q.H., Zhu, M.H., Rong, H.B., Xu, Y.M., Qian, Y.N., et al. (2007) Effects of Nebulized Ketamine on Allergen-Induced Airway Hyperresponsiveness and Inflammation in Actively Sensitized Brown-Norway Rats. Journal of Inflammation, 4, Article No. 10. https://doi.org/10.1186/1476-9255-4-10

[9] Laurant, P., Touyz, R.M. and Schiffrin, E.L. (1997) Effect of Magnesium on Vascular Tone and Reactivity in Pressurized Mesenteric Resistance Arteries from spontaneously Hypertensive Rats. Canadian Journal of Physiology and Pharmacology, 75, 293-300. https://doi.org/10.1139/y97-044

[10] James, M.F. (1985) Magnesium Sulfate in Pheochromocytoma. Anesthesiology, 62, 189-201.

[11] Nakashima, H., Katayama, T., Honda, Y., Suzuki, S. and Yano, K. (2004) Cardioprotective Effects of Magnesium Sulfate in Patients Undergoing Primary Coronary Angioplasty for Acute Myocardial Infarction. Circulation Journal, 68, 23-28. https://doi.org/10.1253/circj.68.23

[12] Turlapaty, P.D. and Altura, B.M. (1978) Extracellular Magnesium Ions Control Calcium Exchange and Content of Vascular Smooth Muscle. European Journal of Pharmacology, 52, 421-423. https://doi.org/10.1016/0014-2999(78)90303-5

[13] Borazan, H., Kececioglu, A., Okesli, S. and Otelcioglu, S. (2012) Oral Magnesium Lozenge Reduces Postoperative Sore Throat: A Randomized, Prospective, PlaceboControlled Study. Anesthesiology, 117, 512-518. https://doi.org/10.1097/ALN.0b013e3182639d5f

[14] Gupta, S.K., Tharwani, S., Singh, D.K. and Yadav, G. (2012) Nebulized Magnesium for Prevention of Postoperative Sore Throat. British Journal of Anaesthesia, 108, 168169. https://doi.org/10.1093/bja/aer437 